\title{
Hepatic De Novo Lipogenesis Is Present in Liver-Specific ACC1-Deficient Mice ${ }^{\nabla} \dagger$
}

\author{
Naomoto Harada, ${ }^{1}$ Zenjun Oda, ${ }^{1}$ Yoshikazu Hara, ${ }^{2}$ Koji Fujinami, ${ }^{2}$ Mayumi Okawa, ${ }^{1}$ \\ Katsuya Ohbuchi, ${ }^{2}$ Mari Yonemoto, ${ }^{2}$ Yuika Ikeda, ${ }^{2}$ Kenji Ohwaki, ${ }^{2}$ \\ Katsumi Aragane, ${ }^{1}$ Yoshitaka Tamai, ${ }^{1}$ and Jun Kusunoki ${ }^{2 *}$ \\ Departments of Pharmacology ${ }^{1}$ and Metabolic Disorder Research, ${ }^{2}$ Tsukuba Research Institute, \\ Banyu Pharmaceutical Co., Ltd., 3 Okubo, Tsukuba, Ibaraki 300-2611, Japan
}

Received 22 June 2006/Returned for modification 3 October 2006/Accepted 17 December 2006

\begin{abstract}
Acetyl coenzyme A (acetyl-CoA) carboxylase (ACC) catalyzes carboxylation of acetyl-CoA to form malonylCoA. In mammals, two isozymes exist with distinct physiological roles: cytosolic ACC1 participates in de novo lipogenesis (DNL), and mitochondrial ACC2 is involved in negative regulation of mitochondrial $\beta$-oxidation. Since systemic ACC1 null mice were embryonic lethal, to clarify the physiological role of ACC1 in hepatic DNL, we generated the liver-specific ACC1 null mouse by crossbreeding of an $A c c 1^{\text {lox(ex46) }}$ mouse, in which exon 46 of $A c c 1$ was flanked by two loxP sequences and the liver-specific Cre transgenic mouse. In liver-specific ACC1 null mice, neither hepatic Acc1 mRNA nor protein was detected. However, to compensate for ACC1 function, hepatic ACC2 protein and activity were induced 1.4 and 2.2 times, respectively. Surprisingly, hepatic DNL and malonyl-CoA were maintained at the same physiological levels as in wild-type mice. Furthermore, hepatic DNL was completely inhibited by an ACC1/2 dual inhibitor, 5-tetradecyloxyl-2-furancarboxylic acid. These results strongly demonstrate that malonyl-CoA from ACC2 can access fatty acid synthase and become the substrate for the DNL pathway under the unphysiological circumstances that result with ACC1 disruption. Therefore, there does not appear to be strict compartmentalization of malonyl-CoA from either of the ACC isozymes in the liver.
\end{abstract}

Acetyl coenzyme A (acetyl-CoA) carboxylase (ACC) catalyzes the carboxylation of acetyl-CoA to form malonyl-CoA, which is a key molecule in the control of intracellular fatty acid metabolism $(13,16,27)$. ACC has two major isozymes that have different physiological roles based on their distinct subcellular distributions (2). A cytosolic enzyme, ACC1 (ACC $\alpha$; molecular mass, $265 \mathrm{kDa}$ ), supplies malonyl-CoA to fatty acid synthase (FAS) and is committed to de novo lipogenesis (DNL) in many tissues via subsequent nutritional and hormonal regulation $(3,16,27)$. In contrast, $\mathrm{ACC} 2(\mathrm{ACC} \beta$; molecular mass, $280 \mathrm{kDa}$ ) is anchored to the mitochondrial surface via a unique $\mathrm{N}$-terminal domain that includes 20 hydrophobic amino acids $(1,2)$. ACC2 produces malonyl-CoA on the mitochondrial surface. It is well known that malonyl$\mathrm{CoA}$ is a potent endogenous inhibitor of carnitine palmitoyl transferase 1 (CPT-1), which is also located on the mitochondrial surface $(21,26)$. Thus, ACC2 indirectly prevents the influx of fatty acids into the mitochondria and their subsequent $\beta$-oxidation (4).

$\mathrm{ACC} 1$ is ubiquitously expressed in many tissues, but higher levels occur in lipogenic tissues, including the liver and adipose tissue (8). In fact, in animals, $A c c 1$ gene expression and ACC activity are markedly induced either by high carbohydrate

\footnotetext{
* Corresponding author. Mailing address: Tsukuba Research Institute, Banyu Pharmaceutical Co., Ltd., 3 Okubo, Tsukuba, Ibaraki 300-2611, Japan. Phone: 81-29-877-2000. Fax: 81-29-877-2027. E-mail: jun_kusunoki@merck.com.

$\dagger$ Supplemental material for this article may be found at http://mcb .asm.org/.

${ }^{\nabla}$ Published ahead of print on 6 January 2007.
}

feeding or hyperinsulinemia in animals and result in increases in adiposity, lipoprotein secretion, and hepatic fat content (16). It is expected that ACC1 blockade should reduce flux through the DNL pathway in lipogenic tissues and thus reduce adiposity, lipoprotein secretion, and fatty liver $(11,23)$. It is therefore plausible that $\mathrm{ACC} 1$ inhibitors have a therapeutic potential for the treatment of obesity, hyperlipidemia, and fatty liver. We attempted to validate this concept by studying the consequences of genetic disruption of the $A c c 1$ gene in mice, but homozygous systemic deficiency of ACC1 was fatal to the fetus. Our observation is consistent with a recent report by AbuElheiga et al., who showed that $A c c 1$ gene disruption was lethal in the mouse embryo stage (5). Therefore, we generated a mutant mouse lacking ACC1 specifically in the liver by using the Cre/loxP system (28). We then studied the physiological role of ACC1 in the DNL pathway of the liver, which is one of the major lipogenic tissues.

\section{MATERIALS AND METHODS}

Construction of targeting vectors. The $A c c 1$ gene was isolated by screening of a $129 /$ Sv mouse genomic library (Stratagene) with a 589-bp rat cDNA probe that was prepared by PCR with 25 cycles of $94^{\circ} \mathrm{C}$ for $1 \mathrm{~min}, 55^{\circ} \mathrm{C}$ for $1 \mathrm{~min}$, and $72^{\circ} \mathrm{C}$ for 1 min using the following primers: ACC1-rF1 (5'-TACCCATTGCACTGT TTGTG-3') and ACC1-rR1 (5'-CTGGGAACATTCCCGCAAGCCA-3'). A 0.5 -kb SalI-BanI fragment, including most of the carboxyltransferase domain of $A c c 1$, was inserted into the SalI site between two loxP sequences in ploxP3NeopA (Kurabo). For the short and long arms of the homology, 9-kb NcoI-SalI and 1.2-kb NdeI-NcoI fragments were used, respectively. A PGK-DT-a cassette was used for negative selection. G418-resistant embryonic stem (ES) clones were screened by PCR with 35 cycles of $94^{\circ} \mathrm{C}$ for $30 \mathrm{~s}, 60^{\circ} \mathrm{C}$ for $1 \mathrm{~min}$, and $72^{\circ} \mathrm{C}$ for 1 min using the following primers: ACC1-F1 (5'-AGGTCTGAAGAGGAGTTT ACGTCCA-3') and ACC1-R9 (5'-TCAGGCTAGCACATGAAGATGCTAC$\left.3^{\prime}\right)$. The targeted allele $\left[A c c 1^{l o x(e x 46)}\right]$ was confirmed by Southern hybridization 
A

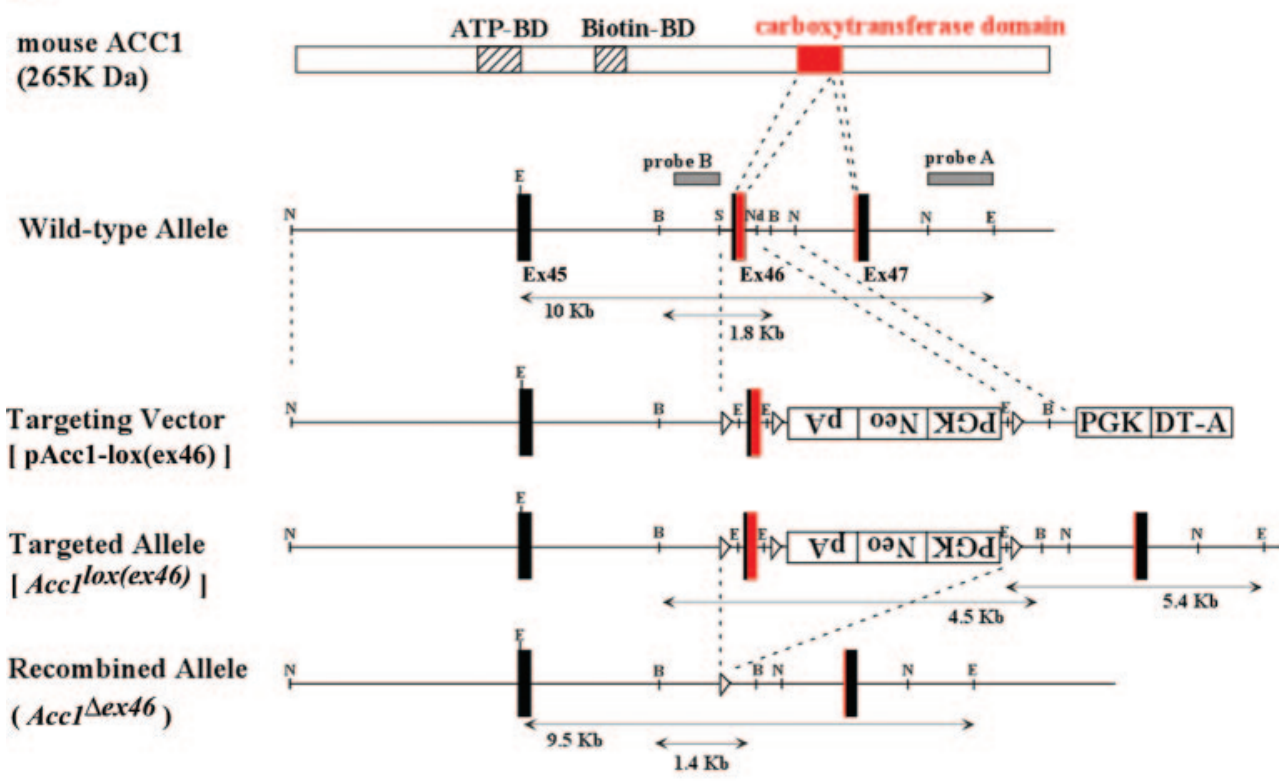

B

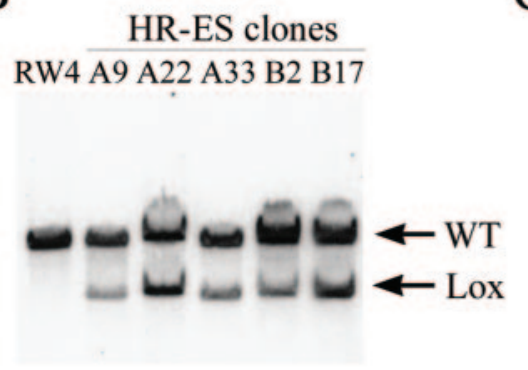

$\mathrm{C}$

F1 intercross

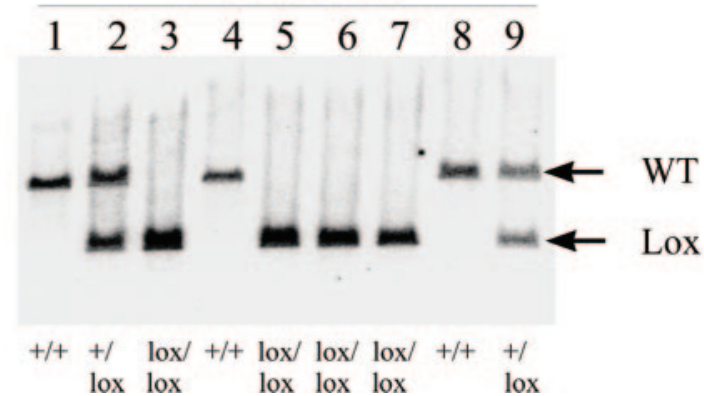

FIG. 1. Conditional deletion of a carboxyltransferase domain of the Acc1 gene by the Cre/loxP system. A. Schematic of the targeting strategy. The structures are shown for ACC1 protein, the wild-type allele, the targeting vector pAcc1-lox(ex46), targeted allele $A c c 1^{\text {lox }(e x 46)}$, and the Cre-recombined allele $\left(A c c 1^{\Delta e x 46}\right)$. The ATP- and biotin-binding domains (ATP-BD and Biotin-BD) are shown as striped boxes, whereas the carboxyltransferase domain in exons 46 and 47 is shown as a red box. The exon numbers are shown as the protein-coding exon numbers. The PGK-neo-bpA and PGK-DT-a cassettes are shown as open boxes. The positions of Southern hybridization probes A and B, which detect EcoRI and BglII fragments, respectively, are also shown. Restriction enzyme sites are the following: B, BamHI; E, EcoRI; N, NcoI; Nd, NdeI; and S, SalI. B. Southern blot analysis of homologous recombination in the targeted ES cell clones. The EcoRI-digested DNA fragments from the parental ES cell line RW4 and targeted ES clones (A9, A22, A33, B2, and B17) were hybridized with probe A. Arrows indicate wild-type (WT; $10 \mathrm{~kb}$ ) and targeted (Lox; $5.4 \mathrm{~kb})$ alleles. C. Southern blot analysis of the intercross offspring of $A c c 1^{+/ l o x(e x 46)}$ heterozygotes. The EcoRI-digested tail DNA from each mouse was hybridized with probe A. The determined genotypes are shown on the bottom.

using an NcoI-EcoRI fragment (probe A), as shown in Fig. 1A. Both wild-type and null alleles $\left(A c c 1^{\operatorname{sex} 46}\right)$ for $A c c 1$ were identified by PCR with 35 cycles of $94^{\circ} \mathrm{C}$ for $30 \mathrm{~s}, 60^{\circ} \mathrm{C}$ for $1 \mathrm{~min}$, and $72^{\circ} \mathrm{C}$ for $1 \mathrm{~min}$ using the following primers: ACC1- $\triangle \mathrm{F} 7$ (5'-GAACTCCTCAAAACAAATCCCCAGA-3') and ACC1- $\triangle \mathrm{R} 8$ (5'-ACCCCTCTCAAGGTATACAGAGAAC- $\left.3^{\prime}\right)$. The null allele was verified by Southern hybridization using an XhoI-SalI fragment (probe B), as shown in Fig. 1A.

Generation of transgenic animals. An ES cell line (RW4) was obtained from Genome Systems Inc., cultured, and electroporated with the targeting vector prepared as described above. Homologous recombinant clones were selected with G418, confirmed by Southern blot analysis (Fig. 1B), and then injected into C57BL/6J blastocysts. Germ line-transmitted chimeras obtained as previously described (24) were crossbred with $\mathrm{C} 57 \mathrm{BL} / 6 \mathrm{~J}$ females, and then the resulting heterozygous offspring $\left[A c c 1^{+/ l o x(e x 46)}\right]$ (N1) were interbred. As shown in Fig. 1C, the number of wild-type, heterozygous, and homozygous mutant mice that were born reflected the Mendelian ratio.

To generate systemic ACC1 null mice (N2), Tg $^{\text {EIIa-cre }}$ transgenic mice (Jackson
Laboratory) (17) were crossbred with $A c c 1^{\operatorname{lox}(e x 46) / / \operatorname{lox}(e x 46)}$ mice (N1). To generate liver-specific ACC1 null mice (N2), the $A c c 1^{\operatorname{lox}(e x 46) / / o x(e x 46)}$ mice (N1) were crossbred with $T g^{\text {Fabpl-cre }}$ mice, which were generated as previously described (12) and then backcrossed to C57BL/6J for six generations (N6). All of the mice that were born were maintained under standard animal housing conditions with a 12-h light/dark cycle (light phase, 7:00 a.m. to 7:00 p.m.; dark phase, 7:00 p.m. to 7:00 a.m.) and were fed ad libitum with a regular chow diet (CE-2; CLEA Japan) or a high-sucrose diet (HSD) containing $67 \%$ sucrose, $8 \%$ cellulose, $20 \%$ casein, $0.2 \%$ choline bitartrate, $3.5 \%$ mineral mix, and $0.3 \%$ DL-methionine (Oriental Yeast). All mice were sacrificed during the diurnal period for analyses (10:00 a.m. to 1:00 p.m., fed state). All animal procedures were done in compliance with National Institutes of Health guidelines and were approved by the Banyu Institutional Animal Care and Use Committee.

Quantitative real-time PCR analysis. Total RNA was purified from livers using Isogen (Wako Pure Chemical Industries) and RNeasy (QIAGEN). The cDNA was synthesized from $0.5 \mu \mathrm{g}$ of DNase I-treated total RNA using a SuperScript First-Strand Synthesis System (Invitrogen) and random hexamer 
primers (Invitrogen). The following primers and probes were used: mACACACBX-253F (5'-GCAGCCCTGGGCACAG-3'), mACACA-CBX-319R (5'-GGG AATACCCGTGGGAGTAGTT-3'), and mACACA-CBX-293T (5'-ACCTGG CTCTGCCAACTACCACGG-3') for Acc1; ACC2m-F (5'-ACAGAGATTT CACCGTTGCGT-3'), ACC2m-R (5'-CGCAGCGATGCCATTGT-3'), and ACC2m-TaM (5'-ACTCGCTTTGGAGGCAACAGGGTCAT-3') for Acc2; mMD.1422-F (5'-CCTCATGGTCAACTACCGCTACT-3'), mMD.1422-R (5'CTTGGAGCCCAGGTAGGAGAT-3'), and mMD.1422-1 (5'-CCTGGAGGA GACAGGCCCCAACA-3') for $\mathrm{Mcd}$; and betaActin.vol2.F (5'-AGGTCATCA CTATTGGCAACGA-3'), betaActin.vol2.R (5'-CACAGGATTCCATACCCA AGAAG-3'), and betaActin.vol2.T (5'-ATGCCCTGAGGCTCTTTTCCAGCC TT-3') for $\beta$-actin. Real-time reverse transcription-PCR (RT-PCR) contained, in a final volume of $10 \mu \mathrm{l}, 0.5 \mathrm{ng}$ of cDNA, $900 \mathrm{nM}$ of the forward and reverse primers for $A c c 1, A c c 2$, or $M c d, 250 \mathrm{nM}$ of probe for $A c c 1, A c c 2$, or $M c d$ labeled with 6-carboxyfluorescein dye, $70 \mathrm{nM}$ of the forward and reverse primers for $\beta$-actin, $200 \mathrm{nM}$ of probe for $\beta$-actin labeled with VIC dye, and $5 \mu \mathrm{l}$ of $2 \times$ TaqMan UMM. The reaction was done in a 384-well optical reaction plate using the PRISM 7900HT Sequence Detection System (Applied Biosystems). Expression data were normalized to the $\beta$-actin expression level.

Western immunoblot analysis. Polyclonal antibodies against ACC1 and ACC2 were prepared by immunizing rabbits with polypeptides SPPQSPTFPEAGH TSLYD and PVKNWMKRRVGPYRRCYF, respectively. Polyclonal anti-MCD antibody was kindly provided by Taro Akiyama from Merck Research Laboratories (Rahway, NJ). The following procedures were carried out on ice or at $4{ }^{\circ} \mathrm{C}$ Mouse tissue sample was homogenized with 10 volumes of $10 \mathrm{mM}$ Tris- $\mathrm{HCl}$ buffer (pH 7.5) containing $225 \mathrm{mM}$ mannitol, $75 \mathrm{mM}$ sucrose, $0.05 \mathrm{mM}$ EDTA, and protease inhibitors (phenylmethylsulfonyl fluoride, aprotinin, pepstatin, leupeptin, and antipain). The homogenate was centrifuged at $48,000 \times g$ for $30 \mathrm{~min}$, and then the resulting supernatant was recentrifuged at $70,000 \times g$ for $60 \mathrm{~min}$ to obtain the cytosol fraction. The protein content in the cytosol fraction was determined using a commercial protein assay kit (Bio-Rad). The cytosol fraction was resolved by sodium dodecyl sulfate-polyacrylamide gel electrophoresis, transferred to a nitrocellulose membrane, and characterized by each antibody coupled with the ECL detection system (GE Healthcare Bio-Sciences Corp.).

De novo lipogenesis. DNL activity was determined by the incorporation of $\left[{ }^{14} \mathrm{C}\right]$ acetate into the lipids (15).

For the liver slices, the liver was taken from mice that had been anesthetized with isoflurane (Escain; Merck Hoei). The incubation medium consisted of Dulbecco's modified Eagle's medium (Invitrogen) and $0.5 \mathrm{mM}\left[1-{ }^{14} \mathrm{C}\right]$ sodium acetate (final concentrations, $29.6 \mathrm{MBq} / \mathrm{mmol}$ and $2.11 \mathrm{GBq} / \mathrm{mmol}$; GE Healthcare Bio-Sciences Corp.) and was aerated with $5 \% \mathrm{CO}_{2}-95 \% \mathrm{O}_{2}$ gas for at least $20 \mathrm{~min}$ prior to use. The liver slices (approximately 20 to $25 \mathrm{mg}$ ) were incubated with the incubation medium for $90 \mathrm{~min}$ at $37^{\circ} \mathrm{C}$. After the incubation period, the liver slices were heated with ethanolic $\mathrm{KOH}$ for $1 \mathrm{~h}$ at $70^{\circ} \mathrm{C}$, and nonsaponified lipids were removed with petroleum ether (30).

For the primary hepatocyte analysis, mouse primary hepatocytes were prepared as previously described (31) and cultured overnight in culture media consisting of Dulbecco's modified Eagle's medium, $10 \%$ fetal bovine serum (HyClone), $100 \mathrm{nM}$ insulin (human recombinant; Novo Nordisk), and $100 \mathrm{nM}$ dexamethasone (Sigma). The hepatocytes were incubated in the culture media containing $74 \mathrm{KBq} / \mathrm{ml}\left[2-{ }^{14} \mathrm{C}\right]$ sodium acetate $(2.07 \mathrm{GBq} / \mathrm{mmol}$; GE Healthcare Bio-Sciences Corp.) for $1 \mathrm{~h}$ and then lysed with $1 \mathrm{~N} \mathrm{NaOH}$ solution.

The resulting aqueous sample solutions obtained either from the liver slices or the hepatocytes were acidified, and then the lipids were extracted with petroleum ether. Radioactivity in the lipid fraction was counted with a liquid scintillation counter (Tri-Carb 2500; Perkin-Elmer).

FAO. Hepatic fatty acid oxidation (FAO) was determined by the liberation of ${ }^{3} \mathrm{H}_{2} \mathrm{O}$ from [ $\left[{ }^{3} \mathrm{H}\right]$ palmitic acid according to a procedure described previously (14), with minor modifications to accommodate for the fact that liver samples were used. The reaction mixture was Krebs-Ringer bicarbonate buffer containing 74 $\mathrm{KBq} / \mathrm{ml}$ 9,10(n)-[ $\left.{ }^{3} \mathrm{H}\right]$ palmitic acid $(1.96 \mathrm{TBq} / \mathrm{mmol}$; GE Healthcare Bio-Sciences Corp.) and $4 \%$ bovine serum albumin (fatty acid free; Wako Pure Chemical Industries), which was aerated with $5 \% \mathrm{CO}_{2}-95 \% \mathrm{O}_{2}$ gas for at least $20 \mathrm{~min}$ prior to use. Liver slices (approximately $10 \mathrm{mg}$ ) were incubated with the reaction mixture for $1 \mathrm{~h}$ at $30^{\circ} \mathrm{C}$. After the incubation period, a $2 \mathrm{M} \mathrm{KCl}-\mathrm{HCl}$ solution was added to the reaction mixture to stop the reaction. The resulting mixture was washed with $\mathrm{CHCl}_{3}$-methanol (2:1) to remove the lipids, including the undesired radioactive materials. The radioactivity of the aqueous phase was counted with a liquid scintillation counter (Tri-Carb 2500; Perkin-Elmer).

Hepatic triglyceride content. Total lipids in the liver were extracted by the procedure described by Folch et al. (10). After drying under nitrogen flow, the extracts were dissolved in isopropanol, and the sample triglyceride (TG) content was determined enzymatically using a commercial assay kit (Determiner L TG II; Kyowa Medex).

Malonyl-CoA content. Livers (50 to $100 \mathrm{mg}$ ) were homogenized with $10 \%$ trichloroacetic acid on ice. After centrifugation, the supernatant was applied to a water-preconditioned Sep-Pak C18 cartridge (Waters). The cartridge was washed with $50 \mathrm{mM} \mathrm{KH_{2 }} \mathrm{PO}_{4}$, and then malonyl-CoA was eluted with $50 \mathrm{mM}$ $\mathrm{KH}_{2} \mathrm{PO}_{4}$ containing $20 \%$ methanol. Malonyl-CoA was determined by incorporation of $\left[{ }^{3} \mathrm{H}\right]$ acetyl-CoA into the palmitic acid in the presence of FAS enzyme as described previously (22).

ACC2 activity. The cytosol fraction prepared as described above in the Western immunoblot analysis section was mixed with an equal volume of $70 \%$ ammonium sulfate solution, stirred for $30 \mathrm{~min}$ at $4^{\circ} \mathrm{C}$, and then centrifuged at $25,000 \times g$ for $30 \mathrm{~min}$. The resulting precipitate was dissolved in buffer A (100 $\mathrm{mM}$ Tris-HCl, pH 7.5, $500 \mathrm{mM} \mathrm{NaCl}, 1 \mathrm{mM}$ EDTA, $1 \mathrm{mM}$ dithiothreitol, and 5\% glycerol) and then stirred with SoftLink Sort Release Avidin Resin (Promega) overnight at $4^{\circ} \mathrm{C}$. After the avidin resin was washed with buffer A, the ACC fraction was eluted with $5 \mathrm{mM}$ biotin in buffer A. Subsequently the anti-ACC2 antibody and protein A agarose (Upstate) were added to the ACC fraction. The resulting mixture was stirred for $3 \mathrm{~h}$ at $4^{\circ} \mathrm{C}$ and then centrifuged at $20,000 \times g$ for $5 \mathrm{~s}$. The resulting resin was washed with phosphate-buffered saline and then suspended in buffer A. ACC activity in the suspension (ACC2 fraction) was measured by fixation of ${ }^{14} \mathrm{CO}_{2}$ as described previously (32).

Blood chemistry. Plasma levels of free fatty acids, TGs, glucose, phospholipids, total cholesterol, lactate dehydrogenase, aspartate aminotransferase, alanine aminotransferase, and 3-hydroxybutyric acid were measured using standard commercial assay kits.

Statistical analysis. All data are shown as means \pm standard errors of the means. Statistical differences between groups were examined using Student's $t$ test. $P<0.05$ was considered statistically significant.

\section{RESULTS}

Generation of systemic ACC1 null mice. At first, we tried to generate ACC1 null mice to study the impact of the systemic disruption of ACC1 in mice. The $A c c 1^{\Delta e x 46}$ allele was generated by crossing $A c c 1^{\operatorname{lox}(e x 46) / / \operatorname{lox}(e x 46)}$ mice with a transgenic mouse line $\left(T g^{\text {EII-Cre }}\right)$ expressing Cre recombinase in the early mouse embryo under the control of the adenovirus EIIa promoter. The genotype of the offspring was confirmed by Southern blot hybridization analysis (see Fig. S1A in the supplemental material). Since neither native nor short truncated mutant ACC1 protein was expressed from the $A c c 1^{\text {sex46 }}$ allele (see Discussion), we designated heterozygous mutant mice $A c c 1^{+/-}$. When $A c c 1^{+--}$mice were interbred, wild-type and $A c c 1^{+/-}$pups were born in a 1:2 ratio, and both genotypes grew normally (see the table in the supplemental material). In contrast, no $A c c 1^{-1-}$ pups were born, indicating that genetic disruption of $A c c 1$ was lethal to the embryo. To determine at what stage the genetic disruption was lethal, embryos from heterozygous intercrosses were examined at 3.5 to 9.5 days postcoitum (dpc) and were genotyped using PCR (see Fig. S1B and the table in the supplemental material). At $3.5 \mathrm{dpc}$ (preimplantation) and $6.5 \mathrm{dpc}$, all genotypes, including $A c \mathrm{Cl}^{-1-}$ embryos, were present with a Mendelian ratio. However, at $7.5 \mathrm{dpc}, A c c 1^{-1-}$ embryos showed an apparent morphological abnormality and were much smaller in size than their control littermates (see Fig. S1C in the supplemental material). Since ACC1 is a cytosolic enzyme that supplies malonyl-CoA to the FAS enzyme and is committed to DNL in many tissues (16), our data indicate that fatty acid (FA) derived from this pathway is essential in the early stage of embryonic development. Very recently, Abu-Elheiga et al. reported the same results showing that disruption of $A c c 1$ was lethal to mouse embryos (5). In addition, Fasn (fatty acid synthase) knockout (KO) mice have also been reported to not survive the embryonic stage (9). Hence, 
A

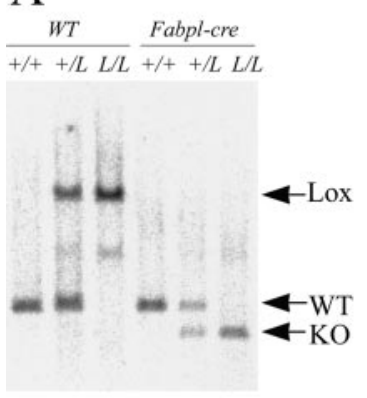

B

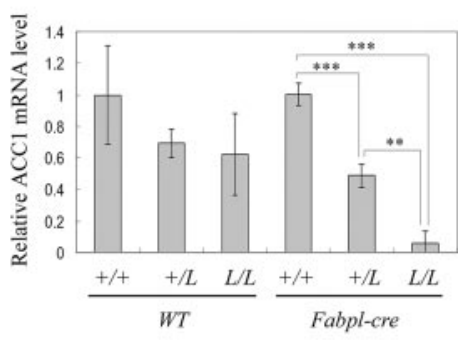

$\mathrm{C}$

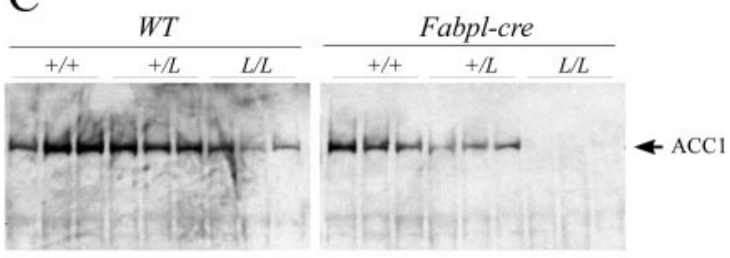

$\alpha-\mathrm{ACCl} \mathrm{Ab}$

FIG. 2. Conditional KO of the $A c c 1$ gene in liver. A. Southern blot analysis of the liver DNA from the wild-type $(+/+), A c c 1^{+/ l o x(e x 46)}$ $(+/ \mathrm{L})$, and $A c c 1^{l o x(e x 46) / l o x(e x 46)}(\mathrm{L} / \mathrm{L})$ mice with or without the Fabpl-cre transgenic allele. The BglII-digested DNA fragments were hybridized with probe B. Arrows indicate targeted (Lox; $4.5 \mathrm{~kb}$ ), wild-type (WT; $1.8 \mathrm{~kb}$ ), and recombined (KO; $1.4 \mathrm{~kb})$ alleles. B. Relative amount of hepatic Acc1 mRNA in each genotype $(n=3)$. The Acc1 expression level was measured by quantitative real-time PCR analysis, normalized with the endogenous $\beta$-actin mRNA level, and is shown as an amount relative to that in the wild-type mice. $* *, P<0.01 ; * * *, P<0.001$. C. Western blot analysis of hepatic ACC1 protein. Total protein was loaded on gradient (3\% to $8 \%$ ) polyacrylamide gel electrophoresis gel $(50 \mu \mathrm{g} / \mathrm{lane})$ and detected with anti-ACC1 antibody (Ab).

the DNL pathway can be considered to be the sole source of FA and is essential in the early stage of embryonic development.

With quantitative real-time PCR, substantial expression levels of Acc1 mRNAs were confirmed in wild-type embryos at 7.5 dpc (approximately 20\% of the level in the adult liver). However, Acc2 mRNA levels were nearly undetectable (see Fig. S1D in the supplemental material), indicating that ACC1 is the sole isozyme committed to the DNL pathway in this stage.
Generation of liver-specific ACC1 null mice. The Acc1 gene was specifically disrupted in the liver by crossbreeding Acc1 $1^{\text {lox(ex46)/lox(ex46) }}$ mice and Fabpl-cre transgenic mice (12), which express Cre specifically in the liver. On Southern hybridization analysis, the recombined $\mathrm{KO}$ allele in the liver sample was found to be either from $A c c 1^{\operatorname{lox}(e x 46) / l o x(e x 46)} \mathrm{Tg}^{\text {Fabpl-cre }}$ or $A c c 1^{+/ l o x(e x 46)} \mathrm{Tg}^{\text {Fabpl-cre }}$ mice but not from $\mathrm{Acc1} 1^{+/+} \mathrm{Tg}^{\text {Fabpl-cre }}$ or other mice harboring no Fabpl-cre transgenic allele (Fig. 2A). The recombined $\mathrm{KO}$ allele was not detected in the tail sample of any animal group, suggesting that ACC1 was not disrupted in other tissues (data not shown). Quantitative realtime PCR analysis showed that the Acc1 mRNA level was decreased by more than $95 \%$ in the livers from Acc1 $1^{\text {lox(ex46)/lox(ex46) }} \mathrm{Tg}^{\text {Fabpl-cre }}$ mice and by approximately $50 \%$ in the livers from $\mathrm{Accl}^{+/ \operatorname{lox}(e x 46)} \mathrm{Tg}^{\text {Fabpl-cre }}$ mice compared to wild-type mice (Fig. 2B). Consistent with these results, Western blot analysis showed that ACC1 protein was not detected in the livers obtained from $A c c 1^{\operatorname{lox}(e x 46) / l o x(e x 46)}$ Tg Fabpl-cre mice (Fig. 2C). Moreover, it was confirmed that the Accl mRNA level was not decreased in other tissues from Acc1 $1^{\text {lox(ex46)/lox(ex46) }} T g^{\text {Fabpl-cre }}$ mice, e.g., brain, lung, heart, stomach, small intestine, large intestine, spleen, kidney, white adipose tissue, skin, muscle, and testis (see Fig. S2 in the supplemental material), indicating that liver-specific disruption of Accl had been successfully achieved. Interestingly, the hepatic Accl mRNA level in Accl lox(ex46)/lox(ex46) WT and $A c c 1^{+/ l o x(e x 46)} W T$ mice was lower than in wild-type mice (Fig. $2 \mathrm{~B})$, suggesting that this mutant allele $\left[A c c 1^{\text {lox(ex46) }}\right]$ is hypomorphic in the absence of Cre-mediated recombination.

Phenotypes in liver-specific ACC1 null mice on chow diet. In the present study, 9-week-old male and female Acc1 ${ }^{\text {lox(ex46)/lox(ex46) }} \mathrm{Tg}^{\text {Fabpl-cre }}$ (referred to as "Acc1 cKO" in this section) mice and two control groups of littermate mice,

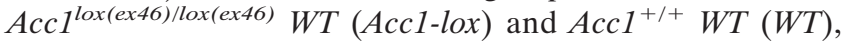
were used. $A c c 1$ cKO mice grew normally and looked normal. Their livers also appeared normal at necropsy. Blood chemistry data showed that no abnormalities were present in Acc1 cKO mice (Table 1). The plasma aspartate aminotransferase level was slightly but significantly increased in male Acc1-lox and Accl cKO mice compared with WT mice. However, this increased level was considered to be within the normal range based on our background data and on the fact that this finding was not reproducible (data not shown).

TABLE 1 . Body weight and blood chemistry ${ }^{a}$

\begin{tabular}{|c|c|c|c|c|c|c|c|c|c|c|}
\hline $\begin{array}{l}\text { Gender } \\
\text { and cell } \\
\text { type }\end{array}$ & BW (g) & $\begin{array}{c}\text { FFA } \\
(\mu \text { Eq/liter })\end{array}$ & TG (mg/dl) & Glu (mg/dl) & PL (mg/dl) & $\mathrm{TC}(\mathrm{mg} / \mathrm{dl})$ & $\begin{array}{c}\text { LDH } \\
\text { (IU/liter) }\end{array}$ & $\begin{array}{c}\text { AST } \\
\text { (IU/liter) }\end{array}$ & $\begin{array}{c}\text { ALT } \\
\text { (IU/liter) }\end{array}$ & $\begin{array}{c}\text { 3-HBA } \\
(\mu \mathrm{mol} / \text { liter })\end{array}$ \\
\hline \multicolumn{11}{|l|}{ Male } \\
\hline WT & $24.9 \pm 1.0$ & $327.8 \pm 75.6$ & $66.6 \pm 5.8$ & $220.6 \pm 11.5$ & $143.0 \pm 7.2$ & $71.2 \pm 4.9$ & $77.6 \pm 3.7$ & $30.2 \pm 0.7$ & $19.6 \pm 1.1$ & $172.4 \pm 10.9$ \\
\hline Lox & $24.9 \pm 0.3$ & $435.0 \pm 49.6$ & $52.8 \pm 11.8$ & $228.5 \pm 21.2$ & $141.0 \pm 5.8$ & $70.0 \pm 4.2$ & $93.5 \pm 18.0$ & $38.8 \pm 3.4^{*}$ & $25.0 \pm 4.1$ & $166.0 \pm 37.4$ \\
\hline cKO & $24.5 \pm 0.4$ & $313.2 \pm 69.7$ & $82.0 \pm 22.2$ & $230.4 \pm 27.1$ & $131.2 \pm 7.0$ & $57.8 \pm 5.1$ & $130.4 \pm 39.0$ & $47.4 \pm 6.0^{*}$ & $30.2 \pm 5.0$ & $194.0 \pm 18.8$ \\
\hline \multicolumn{11}{|l|}{ Female } \\
\hline WT & $20.6 \pm 0.3$ & $437.0 \pm 45.5$ & $66.8 \pm 14.5$ & $193.6 \pm 9.5$ & $130.6 \pm 12.5$ & $64.8 \pm 7.9$ & $72.0 \pm 4.8$ & $38.6 \pm 3.2$ & $18.0 \pm 1.3$ & $194.6 \pm 35.5$ \\
\hline Lox & $20.8 \pm 0.4$ & $351.2 \pm 81.7$ & $49.8 \pm 15.2$ & $237.8 \pm 13.3^{*}$ & $132.6 \pm 3.6$ & $64.0 \pm 2.2$ & $77.0 \pm 2.5$ & $38.0 \pm 3.4$ & $18.8 \pm 1.4$ & $168.2 \pm 18.8$ \\
\hline $\mathrm{cKO}$ & $20.0 \pm 0.4$ & $282.2 \pm 55.5$ & $38.6 \pm 10.2$ & $214.4 \pm 12.7$ & $138.6 \pm 6.4$ & $70.4 \pm 4.8$ & $80.2 \pm 1.0$ & $40.0 \pm 1.3$ & $20.8 \pm 2.3$ & $182.4 \pm 25.0$ \\
\hline
\end{tabular}

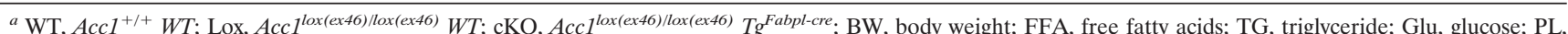
phospholipids, TC, total cholesterol; LDH, lactate dehydrogenase; AST, aspartate aminotransferase; ALT, alanine aminotransferase; 3-HBA, 3-hydroxybutyric acid. *, $P<0.05$ compared to WT. Data are expressed as average results \pm standard errors $(n=4$ to 5$)$. 
A

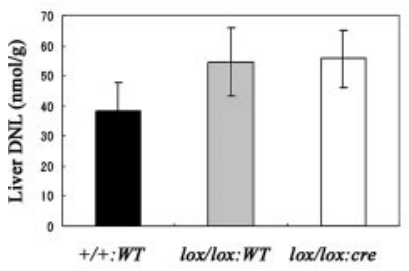

C

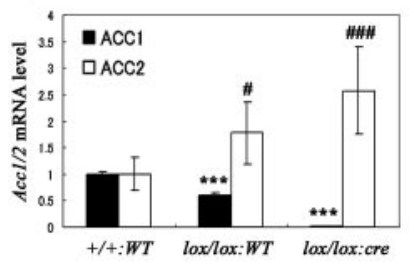

E

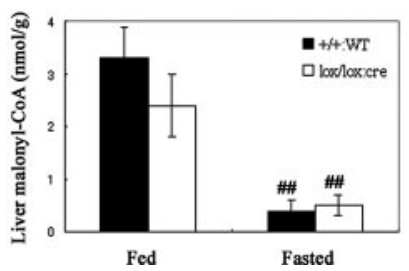

B

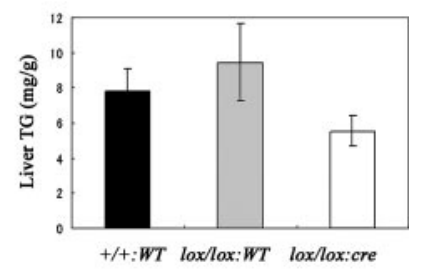

D

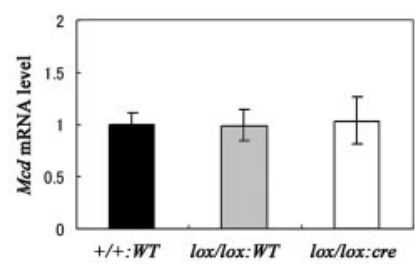

F

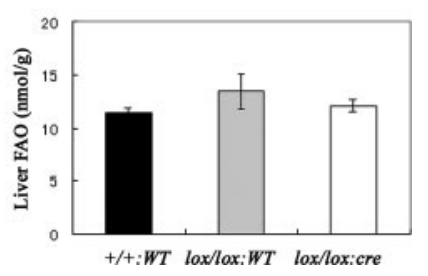

FIG. 3. Key parameters related to the DNL pathway in the liver. (A) DNL and (B) TG levels in the livers obtained from $A c c 1^{+/+} W T$

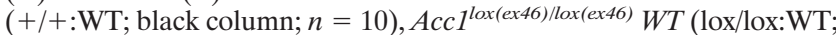
gray column; $n=9$ ), and Acc1 lox(ex46)/lox(ex46) $T g^{\text {Fabpl-cre (lox/lox:cre; }}$ open column; $n=10$ ) mice. (C) Relative Acc1 (black column) and Acc2 (open column) and (D) Mcd mRNA levels in the livers obtained from $+/+$ :WT $(n=10)$, lox/lox:WT $(n=9)$, and lox/lox:cre $(n=10)$ mice. ***, $P<0.001$ compared with $+/+$ :WT (for Acc1); \#, $P<0.05$; \#\#\#, $P<0.001$ compared with $+/+:$ WT (for $A c c 2$ ). (E) MalonylCoA level in the livers obtained from $+/+$ :WT (black column; $n=5$ ) and lox/lox:cre (open column; $n=6$ ) mice fed with a normal chow diet or fasted for $16 \mathrm{~h}$. \#\#, $P<0.01$ for fed versus fasted groups within the same genotype. (F) FAO in the livers obtained from $+/+$ :WT (black column; $n=10$ ), lox/lox:WT (gray column; $n=9$ ), and lox/lox:cre (open column; $n=11$ ) mice. Each column represents average results \pm standard errors.

Next, we evaluated whether the genetic disruption of Acc1 results in a decrease of hepatic DNL activity. Surprisingly, hepatic DNL activity in $A c c 1$ cKO mice was almost comparable to that seen in Acc1-lox or WT mice (Fig. 3A). The hepatic TG content in $A c c 1$ cKO mice tended to be reduced, but not significantly (Fig. 3B). To determine the reason why hepatic DNL was not changed in $A c c 1$ cKO mice, we measured both the $A c c 1$ and $A c c 2$ mRNA levels in the liver using quantitative real-time PCR. As expected, hepatic Accl mRNA levels were decreased by $98 \%$ in $A c c 1$ cKO mice compared to $W T$ mice (Fig. 3C). In contrast, hepatic Acc2 mRNA levels were increased by 2.6 times in $A c c 1$ cKO mice compared to $W T$ mice (Fig. 3C). Consistently, ACC2 protein level determined by Western blot analysis was 1.4 times higher in Acc1 cKO mice (Fig. 4A and B). Also, ACC activity in the ACC2 fraction obtained by immunoprecipitation with anti-ACC2 antibody was 2.2 times higher in Accl cKO mice (Fig. 4D). This indicates that ACC2 was induced to compensate for the genetic

A

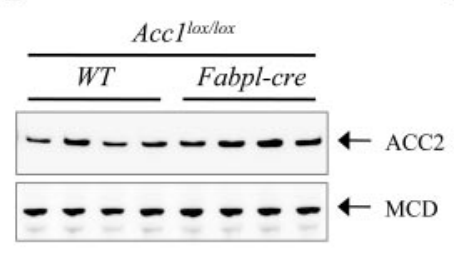

B

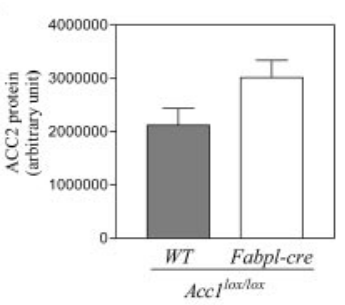

C

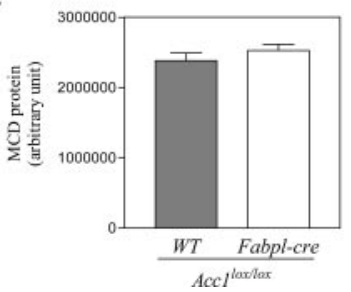

D

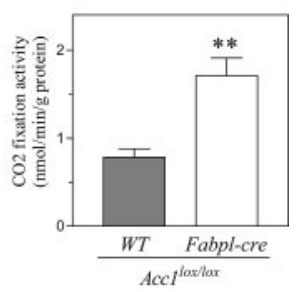

FIG. 4. ACC2 and MCD levels in the liver from Acc1-lox and Acc1 cKO mice. (A) Immunoblot images of $\mathrm{ACC} 2$ and MCD proteins. Quantification of immunoblot images of ACC2 (B) and MCD (C) proteins in the liver from Accl-lox (gray column; $n=4$ ) and Accl cKO (open column; $n=4$ ). (D) ACC2 activity in the liver from Acc1-lox (gray column; $n=4$ ) and Acc1 cKO (open column; $n=4$ ). Each column represents average results \pm standard errors. $* *, P<0.01$.

disruption of Acc1. The hepatic mRNA levels of Mcd (malonyl-CoA decarboxylase [MCD]), which catalyzes malonyl-CoA degradation $(6,25)$, were the same in the three genotypes (Fig. $3 \mathrm{D})$. In agreement with this, the hepatic MCD protein level determined by Western blot analysis was almost the same for Accl-lox and Accl cKO mice (Fig. 4A and C).

To obtain further insights into $A c c 1$ cKO mice, we prepared additional samples from each genotype for further analysis of the malonyl-CoA level and the FAO in the liver. Again, there was no significant difference in either the hepatic DNL or the TG content among the genotypes, and compensatory induction of Acc2 mRNA was again observed (data not shown). As expected, hepatic malonyl-CoA levels were not significantly different between wild-type and $A c c 1$ cKO mice in both fed (wild type, $3.3 \pm 0.6$ versus $A c c 1 \mathrm{cKO} ; 2.4 \pm 0.6 \mathrm{nmol} / \mathrm{g}$ ) and fasted states (wild type, $0.4 \pm 0.2$ versus $A c c 1 \mathrm{cKO} ; 0.5 \pm 0.2$ $\mathrm{nmol} / \mathrm{g}$ ) (Fig. 3E). Liver FAO was the same in the three genotypes (Fig. $3 \mathrm{~F}$ ), despite the fact that $A c c 2$ mRNA was increased in $A c c 1$ cKO mice.

De novo lipogenesis in primary hepatocytes isolated from liver-specific ACC1 null mice. In order to confirm whether malonyl-CoA was derived from ACC activity, we prepared primary hepatocytes from $A c c 1$ cKO mice to study the effect of 5-(tetradecyloxyl)-2-furancarboxylic acid (TOFA), an ACC1 and ACC2 inhibitor, on DNL activity in the hepatocytes (20). As shown in Fig. 5, TOFA inhibited DNL activity in a dosedependent manner and completely inhibited the activity at 10 $\mu \mathrm{M}$, indicating that most of the malonyl-CoA that was present in the hepatocytes was derived from ACC activity.

Effect of a high-sucrose diet on liver TG and de novo lipogenesis in liver-specific ACC1 null mice. Ten-week-old male Acc1 cKO [Acc1 lox(ex46)/lox(ex46) $\left.T g^{\text {Fabpl-cre }}\right]$ and Acc1-lox $\left[A c c 1^{\operatorname{lox}(\operatorname{ex} 46) / \operatorname{lox}(\operatorname{ex} 46)} \mathrm{WT}\right]$ mice were fed with a high-sucrose diet (HSD) (67\% sucrose) for 3 days. Liver TG content and 


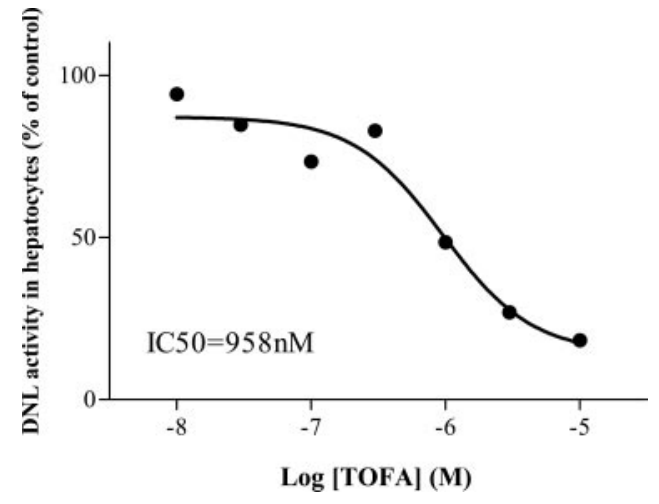

FIG. 5. Inhibitory effect of TOFA on DNL in primary hepatocytes isolated from $A c c 1 \mathrm{cKO}$ mice. Primary hepatocytes prepared from Acc1 cKO mice were incubated with TOFA $(10 \mathrm{nM} \sim 10 \mu \mathrm{M})$. Each symbol represents the average of two or three triplicate experiments and is shown as a percentage of control DNL activity.

DNL in the HSD-fed Acc1-lox mice were 1.4 and 4.2 times higher, respectively, than those in the Acc1-lox mice fed with a regular chow diet (data not shown). Liver TG content in the HSD-fed $A c c 1$ cKO mice was decreased by approximately $70 \%$ compared to that in the HSD-fed Acc1-lox mice (Fig. 6A). Liver DNL in the HSD-fed $A c c 1$ cKO mice was slightly decreased by approximately $25 \%$, in contrast to that in the HSDfed Acc1-lox mice (Fig. 6B), but was still 3.2 times higher than that in Acc1-lox mice with the regular chow diet (data not shown).

\section{DISCUSSION}

Since $A c c 1$ knockout mice do not survive the embryonic stage, we generated an Acc1-lox mouse, in which exon 46 of the $A c c 1$ gene was flanked by two loxP sequences to generate $A c c 1$ conditional knockout mice. We then crossbred the Accl-lox mice with liver-type fatty acid binding protein (Fabpl)-cre transgenic mice (12) to generate liver-specific ACC1 null mice.

On quantitative real-time PCR analysis, the expression of $A c c 1$ mRNA from the $A c c 1^{\text {lox(ex46) }}$ allele was approximately half of that from the wild-type allele (Fig. 2B); this suggests that this mutant allele was hypomorphic, possibly due to the interference of gene expression by the insertion of the PGKneo cassette into intron 46 (18).

If exon 46 was removed by Cre-mediated recombination, splicing from exon 45 to exon 47 would generate a stop codon within exon 47 , leading to the production of a short truncated mutant ACC1 protein (calculated molecular mass, $219 \mathrm{kDa}$ ). However, Western blot analysis showed that neither native nor the supposed mutant $\mathrm{ACC} 1$ protein was detected in the liver samples obtained from the liver-specific ACC1 null mice (Fig. $2 C)$. Since the anti-ACC1 antibody that was used here is supposed to recognize amino acid residues 1258 to 1275 , which are encoded in exon 30 of ACC1 protein, it is likely that the mutant $\mathrm{ACC} 1$ protein would have been detected by the antibody if it were present. Hence, this suggests that, by the deletion of exon 46, which generates a null mutant allele, the mutant ACC1 protein is eventually not produced. More im-
A

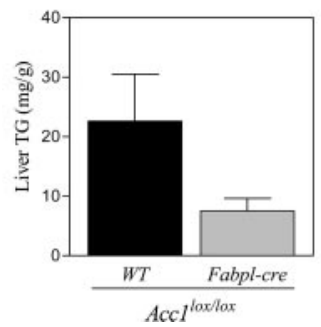

B

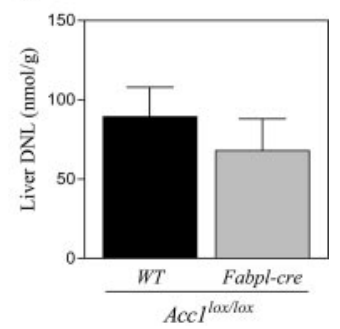

FIG. 6. Liver TG (A) and DNL (B) in Acc1-lox and Acc1 cKO mice on HSD. Acc1-lox (black column; $n=6$ ) and Acc1 cKO mice (gray column; $n=4$ ) were fed with HSD for 3 days. Each column represents average results \pm standard errors.

portantly, by using the above method, we successfully generated liver-specific ACC1 null mice.

It is believed that ACC1 is solely committed to DNL in many tissues, including the liver, and is under nutritional and hormonal regulation $(16,23)$. On the other hand, the mitochondrial type of ACC isozyme (2), ACC2, produces malonyl-CoA, which is known to be a potent endogenous inhibitor of carnitine palmitoyl transferase-1 (CPT-1) on the mitochondrial surface $(21,26)$. Since CPT-1, which is also located on the mitochondrial surface, uptakes long-chain fatty acyl-CoA into the mitochondria and facilitates subsequent FAO, it is thought that ACC2 negatively controls mitochondrial FAO $(4,27)$. In addition, it has been suggested that malonyl-CoA synthesized by ACC 2 cannot access the FAS enzyme and cannot be committed to DNL due to the strict compartmentalization of malonyl-CoA derived from either ACC1 or $\operatorname{ACC} 2(4,5)$. Therefore, liver-specific ACC1 null mice should lose hepatic DNL activity. However, unexpectedly, our present study demonstrated that hepatic DNL in liver-specific ACC1 null mice was almost at the same level as in WT mice (Fig. 3A). This finding strongly indicates that $\mathrm{ACC} 1$ is not the essential enzyme for DNL in the mouse liver.

Based on the findings in $A c c 2 \mathrm{KO}$ mice, it has been suggested that most hepatic malonyl-CoA is derived from ACC1 and that malonyl-CoA from $\mathrm{ACC} 2$ is almost negligible in the mouse liver (4). Therefore, with ACC1 disruption, the hepatic malonyl-CoA level should have been negligible. However, in the present study, hepatic malonyl-CoA was only slightly decreased (the difference was not statistically significant), and the level was almost the same among genotypes both in the fed and the fasted state (Fig. 3E). Furthermore, quantitative RT-PCR analysis showed that hepatic $A c c 2$ mRNA was induced by approximately 2.6 times as a compensatory mechanism to hepatic $A c c 1$ knockout (Fig. 3C). ACC2 protein and activity were consistently increased by approximately 1.4 and 2.2 times, respectively, in the liver of liver-specific ACC1 null mice (Fig. $4 \mathrm{~A}, \mathrm{~B}$, and D). Therefore, it is likely that this compensatory induction of ACC2 can produce a large amount of malonylCoA to maintain a physiological level of malonyl-CoA in liver lacking the ACC1 enzyme. In addition, since the levels of malonyl-CoA decarboxylase (MCD) protein and $M c d$ mRNA were found to be the same among the genotypes (Fig. 3D and $4 \mathrm{~A}$ and $\mathrm{C}$ ), it is unlikely that $\mathrm{MCD}$, which is a key regulator of the intracellular malonyl-CoA level $(6,25)$, is a major contrib- 
utor in the regulation of hepatic malonyl-CoA levels in ACC1disrupted livers.

Quite strikingly, DNL activity was completely inhibited by TOFA, an inhibitor for both ACC1 and ACC2 (20), in primary hepatocytes isolated from liver-specific ACC1 null mice (Fig. 5). This finding strongly indicates that malonyl-CoA derived from ACC2 can access the FAS enzyme and is involved in the hepatic DNL pathway in the ACC1-disrupted liver. Recently, an alternative splice form of $A c c 2$, which lacks approximately $200 \mathrm{~N}$-terminal amino acids, including the sequence responsible for binding to the mitochondrial outer membrane, was reported (7). It has been suggested that the splice variant is localized in the cytosol and is committed to DNL. However, since the $A c c 2$ variant was almost undetectable on quantitative RT-PCR analysis in the liver sample from either liver-specific ACC1 null or WT mice (data not shown), it is less likely that the variant contributes to the hepatic malonyl-CoA levels seen in liver-specific ACC1 null mice.

Given these results, it is strongly suggested that ACC2 is induced as a compensatory mechanism due to ACC1 disruption to maintain physiological levels of malonyl-CoA in the liver. More importantly, our findings demonstrate that malonyl-CoA from ACC2 not only inhibits CPT-1 activity on the mitochondrial surface but also can access the FAS enzyme in the ACC1-disrupted liver.

In the present study, hepatic TG content tended to be lower in liver-specific ACC1 null mice than in WT mice (Fig. 3B). Very recently, Mao et al. reported that liver-specific ACC1 knockout mice are resistant to an HSD (58.45\% sucrose)induced hepatic steatosis (19). Taken together, it seems that the liver lacking ACC1 cannot handle excess amounts of carbohydrate ingestion. To confirm this point, a further study was conducted in liver-specific ACC1 knockout mice fed with an HSD (67\% sucrose). As shown in Fig. 6A, in contrast to littermate control mice, hepatic TG content was decreased by approximately $70 \%$ in liver-specific ACC1 knockout mice (no statistical significance), suggesting that compensatory induced hepatic ACC2 cannot fully cover physiological function of hepatic ACC1 responding to dietary nutrition. However, hepatic DNLs in both genotypes were not so different (Fig. 6B). One likely reason to explain this discrepancy between hepatic TG and DNL data could be a timing of hepatic DNL measurement. We measured diurnal hepatic DNL activity, which is supposed to be much lower than nocturnal hepatic DNL activity. In contrast to littermate control mice, nocturnal hepatic DNL induction may be limited and much smaller in liverspecific ACC1 knockout mouse. This potential limitation of hepatic DNL induction in liver lacking ACC1 may also limit hepatic TG accumulation induced by carbohydrate ingestion.

Abu-Elheiga et al. have proposed that there are two distinct malonyl-CoA pools for ACC1 and ACC2 in the cell: one in the cytosol, and one in the mitochondria $(4,5)$. They have also hypothesized that the two pools are strictly compartmentalized from each other, since (i) there is distinct intracellular localization of each isozyme; (ii) hepatic FAO was higher in Acc2 KO mice despite the fact that the hepatic malonyl-CoA level was the same in $A c c 2 \mathrm{KO}$ and wild-type mice in the fasted state; and (iii) ACC2 did not correct for ACC1 function in Acc1 KO embryos, leading to lethal damage. However, our data strongly indicate that the malonyl-CoA pool for ACC2 is not strictly compartmentalized in the hepatocyte of liver-specific ACC1 null mice. At this point, there is no clear explanation for the discrepancy between findings of Abu-Elheiga et al. and ours. However, it is possible that, under physiological conditions, the malonyl-CoA derived from either ACC1 or ACC2 does not mix, and that each one is committed to its distinct physiological role (DNL or FAO). However, under these particular unphysiological conditions, it is likely that there is no strict compartmentalization, at least for ACC2. Recently, supporting data has been published by Savage et al. (29). According to their findings in hepatic ACC1 and/or ACC2 knockdown rats using antisense oligonucleotides, each ACC isozyme knockdown led to a 1.5- to 2-fold increase of the hepatic FAO rate. Moreover, knockdown of both ACCs led to an $\sim 4$-fold increase in the hepatic FAO rate in the rats. These observations also imply that malonyl-CoA from ACC1 can access CPT-1 and control mitochondrial FAO. On the other hand, since $A c c 1 \mathrm{KO}$ is lethal in the embryonic stage, it must be that malonyl-CoA derived from ACC2 does not compensate for DNL activity to make the FA that is required for embryonal development. However, it seems that this is not due to the strict compartmentalization of the two isozymes but that it is due to a lack of ACC2 expression in the early stage of embryonic development. Indeed, $A c c 2$ mRNA was not detected in wild-type mouse embryos at $7.5 \mathrm{dpc}$ by quantitative RT-PCR analysis (see Fig. S1D in the supplemental material). Interestingly, liver development was not affected by hepatic ACC1 protein disruption in mice despite the fact that ACC2 is thought not to exist at this stage of liver development: $A c c 2$ mRNA was undetectable in livers isolated from wild-type mouse embryos at $13.5 \mathrm{dpc}$ (data not shown). It could be that, at this stage, adequate amounts of FA are supplied by the mother. Further studies will be required to fill the gap between findings of Abu-Elheiga et al. and ours. It may be that an unknown enzyme having ACC activity contributes to this compensatory increase of malonyl-CoA levels that was observed in the present study.

It is believed that malonyl-CoA synthesized by ACC2 negatively regulates FAO by inhibiting CPT-1 $(21,26)$. In the present study, an almost physiological level of malonyl-CoA was found due to the presence of ACC2 in the liver of liverspecific ACC1 null mice (Fig. 3E). This excess amount of malonyl-CoA ought to have suppressed the basal FAO rate in the mitochondria, because all malonyl-CoA in the mitochondria is supposed to be of ACC2 origin. However, hepatic FAO and serum ketone body levels were comparable in both genotypes (Fig. 3F; Table 1). These data imply that the mitochondrial malonyl-CoA pool was not excessively large and did not reach levels that would suppress FAO, indicating that FAO is physiologically and normally controlled even with increased ACC2 expression. This also suggests that the unnecessary and excess malonyl-CoA produced by $\mathrm{ACC} 2$ that was observed in this study can fill the cytosol pool for malonyl-CoA and eventually participates in DNL to generate FA.

In conclusion, we succeeded in generating liver-specific ACC1 null mice with livers that appeared normal and developed normally. Although hepatic ACC1 protein was absent, hepatic DNL and malonyl-CoA levels were normal in liverspecific ACC1 null mice. In addition, hepatic DNL was completely inhibited by an ACC1/2 inhibitor, TOFA. Furthermore, 
hepatic $A c c 2$ mRNA, protein, and activity were up-regulated in the liver-specific ACC1 null mice. These results strongly indicate that malonyl-CoA synthesized by ACC2 is involved not only in mitochondrial FAO but also in the cytosolic DNL pathway and can adapt to unphysiological conditions due to ACC1 disruption. The findings of the present study should have an impact on the current views regarding malonyl-CoA compartmentalization in the cell. In addition, our data partially support a concept that hepatic ACC1 blockade will reduce flux through the DNL pathway, causing reduced lipoprotein secretion and decreased fatty liver (23). However, since hepatic ACC2 can partially cover ACC1 function as a backup system, tachyphylaxis should be alarmed by the chronic and selective blockade of hepatic ACC1. Blocking both ACC1 and ACC2 may avoid this potential tachyphylaxis and may be more efficacious to improve hepatic steatosis.

\section{ACKNOWLEDGMENTS}

We thank Yasuko Muramatsu for excellent technical assistance, Jun Suzuki and Yoshiki Itoh for constructive criticism, Akio Kanatani for reviewing the manuscript and offering helpful suggestions, and Toshiyuki Takahashi for synthesizing and providing TOFA (all belong to the Banyu Tsukuba Research Institute). Also we are grateful to Taro Akiyama at Merck Research Laboratories (Rahway, NJ) for providing anti-MCD antibody.

\section{REFERENCES}

1. Abu-Elheiga, L., D. B. Almarza-Ortega, A. Baldini, and S. J. Wakil. 1997. Human acetyl-CoA carboxylase 2. Molecular cloning, characterization, chromosomal mapping, and evidence for two isoforms. J. Biol. Chem. 272:1066910677.

2. Abu-Elheiga, L., W. R. Brinkley, L. Zhong, S. S. Chirala, G. Woldegiorgis, and S. J. Wakil. 2000. The subcellular localization of acetyl-CoA carboxylase 2. Proc. Natl. Acad. Sci. USA 97:1444-1449.

3. Abu-Elheiga, L., A. Jayakumar, A. Baldini, S. S. Chirala, and S. J. Wakil. 1995. Human acetyl-CoA carboxylase: characterization, molecular cloning, and evidence for two isoforms. Proc. Natl. Acad. Sci. USA 92:4011-4015.

4. Abu-Elheiga, L., M. M. Matzuk, K. A. Abo-Hashema, and S. J. Wakil. 2001. Continuous fatty acid oxidation and reduced fat storage in mice lacking acetyl-CoA carboxylase 2. Science 291:2613-2616.

5. Abu-Elheiga, L., M. M. Matzuk, P. Kordari, W. Oh, T. Shaikenov, Z. Gu, and S. J. Wakil. 2005. Mutant mice lacking acetyl-CoA carboxylase 1 are embryonically lethal. Proc. Natl. Acad. Sci. USA 102:12011-12016.

6. An, J., D. M. Muoio, M. Shiota, Y. Fujimoto, G. W. Cline, G. I. Shulman, T. R. Koves, R. Stevens, D. Millington, and C. B. Newgard. 2004. Hepatic expression of malonyl-CoA decarboxylase reverses muscle, liver and wholeanimal insulin resistance. Nat. Med. 10:268-274.

7. Barber, M. C., N. T. Price, and M. T. Travers. 2005. Structure and regulation of acetyl-CoA carboxylase genes of metazoa. Biochim. Biophys. Acta 1733: $1-28$.

8. Bianchi, A., J. L. Evans, A. J. Iverson, A. C. Nordlund, T. D. Watts, and L. A. Witters. 1990. Identification of an isozymic form of acetyl-CoA carboxylase. J. Biol. Chem. 265:1502-1509.

9. Chirala, S. S., H. Chang, M. Matzuk, L. Abu-Elheiga, J. Mao, K. Mahon, M. Finegold, and S. J. Wakil. 2003. Fatty acid synthesis is essential in embryonic development: fatty acid synthase null mutants and most of the heterozygotes die in utero. Proc. Natl. Acad. Sci. USA 100:6358-6363.

10. Folch, J., M. Lees, and G. H. Sloane Stanley. 1957. A simple method for the isolation and purification of total lipides from animal tissues. J. Biol. Chem. 226:497-509.

11. Ha, J., and K. H. Kim. 1994. Inhibition of fatty acid synthesis by expression of an acetyl-CoA carboxylase-specific ribozyme gene. Proc. Natl. Acad. Sci. USA 91:9951-9955.
12. Harada, N., Y. Tamai, T. Ishikawa, B. Sauer, K. Takaku, M. Oshima, and M. M. Taketo. 1999. Intestinal polyposis in mice with a dominant stable mutation of the beta-catenin gene. EMBO J. 18:5931-5942.

13. Hardie, D. G. 1989. Regulation of fatty acid synthesis via phosphorylation of acetyl-CoA carboxylase. Prog. Lipid Res. 28:117-146.

14. Ibrahimi, A., A. Bonen, W. D. Blinn, T. Hajri, X. Li, K. Zhong, R. Cameron, and N. A. Abumrad. 1999. Muscle-specific overexpression of FAT/CD36 enhances fatty acid oxidation by contracting muscle, reduces plasma triglycerides and fatty acids, and increases plasma glucose and insulin. J. Biol. Chem. 274:26761-26766.

15. Jamdar, S. C. 1978. Glycerolipid biosynthesis in rat adipose tissue. Influence of adipose-cell size and site of adipose tissue on triacylglycerol formation in lean and obese rats. Biochem. J. 170:153-160.

16. Kim, K. H. 1997. Regulation of mammalian acetyl-coenzyme A carboxylase. Annu. Rev. Nutr. 17:77-99.

17. Lakso, M., J. G. Pichel, J. R. Gorman, B. Sauer, Y. Okamoto, E. Lee, F. W. Alt, and H. Westphal. 1996. Efficient in vivo manipulation of mouse genomic sequences at the zygote stage. Proc. Natl. Acad. Sci. USA 93:5860-5865.

18. Lewandoski, M. 2001. Conditional control of gene expression in the mouse. Nat. Rev. Genet. 2:743-755.

19. Mao, J., F. J. Demayo, H. Li, L. Abu-Elheiga, Z. Gu, T. E. Shaikenov, P. Kordari, S. S. Chirala, W. C. Heird, and S. J. Wakil. 2006. Liver-specific deletion of acetyl-CoA carboxylase 1 reduces hepatic triglyceride accumulation without affecting glucose homeostasis. Proc. Natl. Acad. Sci. USA 103: 8552-8557.

20. McCune, S. A., and R. A. Harris. 1979. Mechanism responsible for 5(tetradecyloxy)-2-furoic acid inhibition of hepatic lipogenesis. J. Biol. Chem. 254:10095-10101.

21. McGarry, J. D., G. F. Leatherman, and D. W. Foster. 1978. Carnitine palmitoyltransferase I. The site of inhibition of hepatic fatty acid oxidation by malonyl-CoA. J. Biol. Chem. 253:4128-4136.

22. McGarry, J. D., M. J. Stark, and D. W. Foster. 1978. Hepatic malonyl-CoA levels of fed, fasted and diabetic rats as measured using a simple radioisotopic assay. J. Biol. Chem. 253:8291-8293.

23. Munday, M. R., and C. J. Hemingway. 1999. The regulation of acetyl-CoA carboxylase-a potential target for the action of hypolipidemic agents. Adv. Enzyme Regul. 39:205-234.

24. Oshima, M., H. Oshima, K. Kitagawa, M. Kobayashi, C. Itakura, and M. Taketo. 1995. Loss of Apc heterozygosity and abnormal tissue building in nascent intestinal polyps in mice carrying a truncated Apc gene. Proc. Natl. Acad. Sci. USA 92:4482-4486.

25. Park, H., V. K. Kaushik, S. Constant, M. Prentki, E. Przybytkowski, N. B. Ruderman, and A. K. Saha. 2002. Coordinate regulation of malonyl-CoA decarboxylase, sn-glycerol-3-phosphate acyltransferase, and acetyl-CoA carboxylase by AMP-activated protein kinase in rat tissues in response to exercise. J. Biol. Chem. 277:32571-32577.

26. Prip-Buus, C., J. P. Pegorier, P. H. Duee, C. Kohl, and J. Girard. 1990. Evidence that the sensitivity of carnitine palmitoyltransferase I to inhibition by malonyl-CoA is an important site of regulation of hepatic fatty acid oxidation in the fetal and newborn rabbit. Perinatal development and effects of pancreatic hormones in cultured rabbit hepatocytes. Biochem. J. 269:409415 .

27. Ruderman, N. B., A. K. Saha, D. Vavvas, and L. A. Witters. 1999. MalonylCoA, fuel sensing, and insulin resistance. Am. J. Physiol. 276:E1-E18.

28. Sauer, B. 1993. Manipulation of transgenes by site-specific recombination: use of Cre recombinase. Methods Enzymol. 225:890-900.

29. Savage, D. B., C. S. Choi, V. T. Samuel, Z. X. Liu, D. Zhang, A. Wang, X. M. Zhang, G. W. Cline, X. X. Yu, J. G. Geisler, S. Bhanot, B. P. Monia, and G. I. Shulman. 2006. Reversal of diet-induced hepatic steatosis and hepatic insulin resistance by antisense oligonucleotide inhibitors of acetyl-CoA carboxylases 1 and 2. J. Clin. Investig. 116:817-824.

30. Stansbie, D., R. W. Brownsey, M. Crettaz, and R. M. Denton. 1976. Acute effects in vivo of anti-insulin serum on rates of fatty acid synthesis and activities of acetyl-coenzyme A carboxylase and pyruvate dehydrogenase in liver and epididymal adipose tissue of fed rats. Biochem. J. 160:413-416.

31. Swift, L. L., M. H. Farkas, A. S. Major, K. Valyi-Nagy, M. F. Linton, and S. Fazio. 2001. A recycling pathway for resecretion of internalized apolipoprotein E in liver cells. J. Biol. Chem. 276:22965-22970.

32. Tanabe, T., S. Nakanishi, T. Hashimoto, H. Ogiwara, J. Nikawa, and S. Numa. 1981. Acetyl-CoA carboxylase from rat liver. Methods Enzymol. 71:5-16. 